\title{
GAS DISCHARGE SWITCH EVALUATION FOR RHIC BEAM ABORT KICKER APPLICATION ${ }^{*}$
}

\author{
Wu Zhang, Jon Sandberg \\ Collider-Accelerator Department \\ Brookhaven National Laboratory \\ Upton, NY 11973, USA
}

\author{
Ron Sheldrake, Colin Pirrie \\ Marconi Applied Technology, UK
}

\begin{abstract}
A gas discharge switch EEV HX3002 is being evaluated at Brookhaven National Laboratory as a possible candidate of RHIC Beam Abort Kicker modulator main switch. At higher beam energy and higher beam intensity, the switch stability becomes very crucial. The hollow anode thyratron used in the existing system is not rated for long reverse current conduction. The reverse voltage arcing caused thyratron hold-off voltage de-rating has been the main limitation of the system operation. To improve the system reliability, a new type of gas discharge switch has been suggested by Marconi Applied Technology for its reverse conducting capability.
\end{abstract}

\section{SYSTEM INTRODUCTION}

In each of the RHIC Blue and Yellow Ring, there is a RHIC Beam Abort Kicker System. They are used to clear the circulating beams at the end of the beam storage, normally once every ten hours, or when beam permit is pulled by any of the ring systems. It consists of five identical high voltage modulators and magnet modules in each of the systems. Ten high voltage modulators were installed in the RHIC tunnel in 1999, directly connected to the kicker magnets. The peak current required [2], to remove the $100 \mathrm{GeV}$ beam safely from the superconducting ring, is $18 \mathrm{kA}$ per module, corresponding to $28 \mathrm{kV}$ charging voltage. And, the beam revolution time is about 12.6 uS. An irregular output current waveform was intentionally designed to avoid deposit high energy particle beam at a single spot of beam absorber.

The RHIC Blue Ring Beam Abort Kicker System was commissioned at beam injection energy level in 1999. Its identical Yellow Ring System became operative in spring 2000. During 2000 RHIC Commissioning Run, Both Yellow Ring and Blue Ring Beam Abort Kicker Systems were operated to remove $66 \mathrm{GeV}$ beam successfully. Last year, RHIC has reached its designed energy level of 100 $\mathrm{GeV}$ with 55 bunch each ring and $1 \times 10^{9}$ ions per bunch. At this level, beam energy is high enough to quench

*Work performed under the auspices of the U.S. Department of Energy. superconducting magnet and cause structural damage. In addition to this, Phobo, a physics experiment down stream of the beam abort magnet, warned that its sophisticated silicon detector could be destroyed if high energy high intensity beam spread onto it. This is a new situation, and it requires immediate protection. Both RHIC Beam Abort Kickers provided essential functionality to protect RHIC and Phobo detector during RHIC 2001 Physics Operation. Tremendous efforts have been spent to improve the kicker performance to meet physics requirement, and further efforts are deemed necessary to ensure high intensity beam operation in the future.

\section{ISSUES AND QUESTS}

The main problem of the RHIC Beam Abort Kicker System is the voltage hold-off. It's partially due to modulator design and construction deficiency and partially due to exceeding thyratron reverse conducting capability. Like most kicker modulators, it uses capacitive energy storage PFN and a hollow anode thyratron. Its current output has a very long and large reverse swing, which is beyond the rating of any existing hollow anode thyratron.

Two types of Hollow Anode Thyratrons, CX1575C and CX3575C, have been evaluated and tested by the RHIC Beam Abort Kicker System designers during its development phase. It was concluded that the reverse current could cause thyratron damages, and extensive thyratron conditioning and frequent replacement are necessary. Several days are required for each thyratron conditioning, and several months for all ten thyratrons to be conditioned or reconditioned. Yet, there is no criterion for how long a pre-conditioned thyratron remains valid for this particular application, and how often it needs to be reconditioned. The RHIC beam Abort Kickers were operated about once every ten hours during normal beam storage, and more frequently during injection tuning process at $4 \mathrm{kV}$ level. At least seven thyratrons were removed from service during last run. Among the five removed CX1575C thyratrons, some were moderately damaged and can be reconditioned for later reuse, and some were seriously damaged cannot be reused. 
A gas switch $\mathrm{HX} 3002$, as shown in Figure 2, was recommended by Marconi Applied Technology for thyratron replacement. It's rated for $38 \mathrm{kV}, 20 \mathrm{kA}$ forward conduction, and $15 \mathrm{kA}$ reverse current conduction.

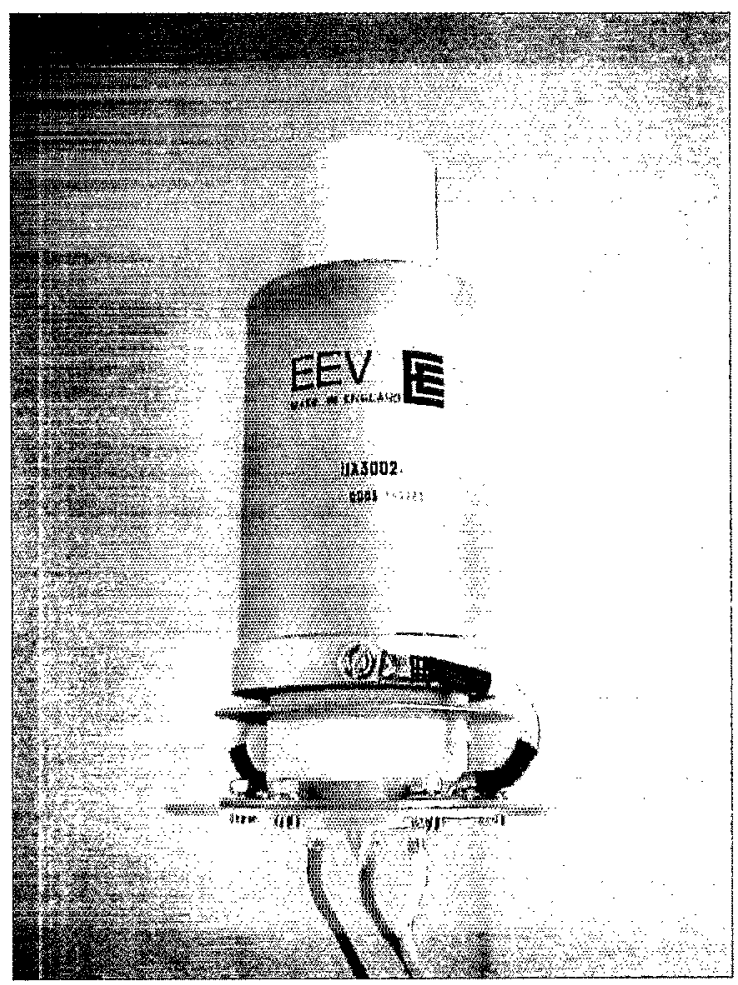

Figure 1. The Marconi Applied Technology's Gas Discharge Switch HX3002 is shown in this picture.

\section{TEST RESULT}

The HX3002 is a deuterium-filled Gas Discharge Switch operating on the left side of the Paschen curve, similar to the larger HX3010 switch. The HX3002 is rated for $38 \mathrm{kV}, 20 \mathrm{kA}$ peak forward conduction. A prototype RHIC Beam Abort Kicker Modulator and a low capacitance high voltage modulator are used for HX3002 tube evaluation. The low capacitance RLC modulator is useful for thyratron and gas discharge switch high voltage conditioning and low current, low energy pulse testing.

Two triggering circuits were suggested by Marconi Applied Technology. One operates with dual trigger; another one uses DC prime and a single trigger. In out tests, we used a $120 \mathrm{~V} \mathrm{DC}$ Prime at Grid 1 and a $900 \mathrm{~V}$ trigger into Grid 2. A 6.0 VAC and a 4.5 VAC were applied to the Cathode heater and Reservoir heater, respectively. The switch tube used in this test had a 3400 shot manufacture test at Marconi.

The HX3002 was conditioned with $5 \mathrm{kV}$ steps up to $35 \mathrm{kV}$. From above $20 \mathrm{kV}$, the tube was checked for its hold-off for eight hours at each level and easily passed the test at $35 \mathrm{kV}$ for 8 hours. Then a sequence of low energy pulse test was done at each voltage level with $5 \mathrm{kV}$ increment up to $35 \mathrm{kV}$. About 300 shot was performed at each voltage level, and about 3500 pulses were accumulated during this test. A 300 more pulses were added to it from a second test run. Figure 2 shows the pulse waveform at $38 \mathrm{kV}$ charging voltage.

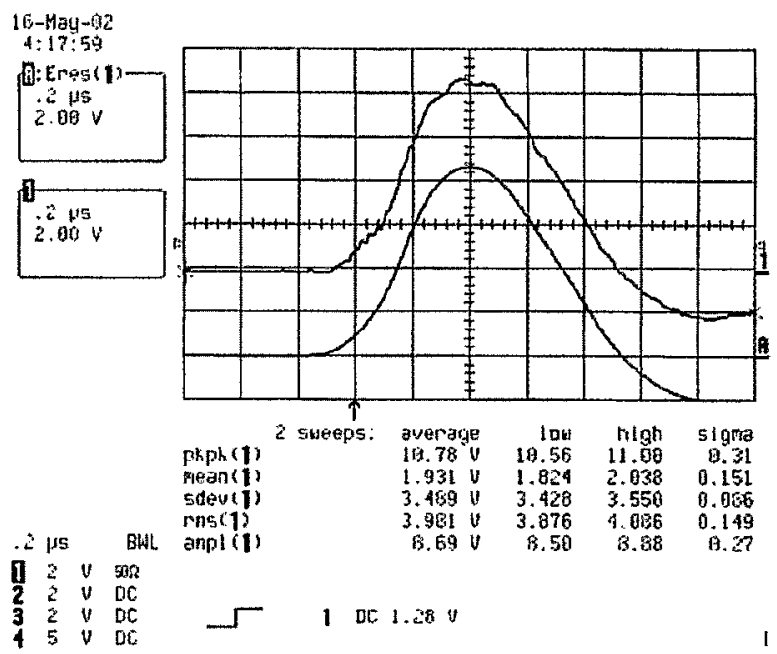

Figure 2. The output current waveform of low energy pulser at $38 \mathrm{kV}$ is shown.

After low energy pulse test, the switch was hi-potted at its peak DC voltage hold-off at $38 \mathrm{kV}$ again for more than 20 hours, and successfully passed it as well.

Next, it was installed in the RHIC Beam Abort Kicker prototype modulator for high energy and high current test. The test was carefully conducted at each voltage level up to $30 \mathrm{kV}$ with $5 \mathrm{kV}$ incremental steps. About 2000 pulses were taken in this test. At $30 \mathrm{kV}$, the peak amplitude is $21.69 \mathrm{kV}$, which is $20 \%$ above the RHIC Beam Abort requirement for peak energy. It's actually exceeded the HX3002 forward current rating of $20 \mathrm{kA}$, but less than the $23 \mathrm{kA}$ level tested at factory. The output waveform is shown in Figure 3, which is identical to the one obtained with thyratron.

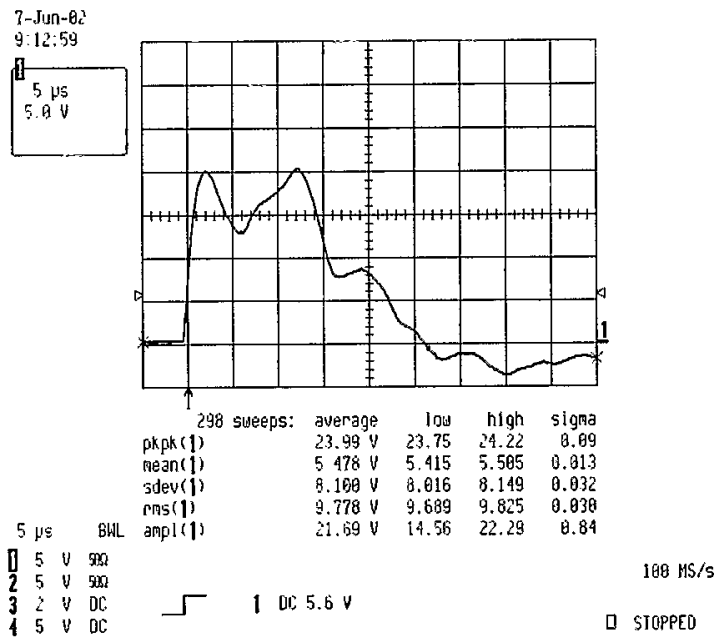

Figure 3. Output Current Waveform at 30kV, $21.69 \mathrm{kA}$. 
It was noticed that at lower anode voltage, the reverse conduction might vary, as shown in Figure 4. This particular picture was taken at $15 \mathrm{kV}$ anode potential. It seems to be a minimal reverse voltage is needed for reverse conduction. The reverse conduction is only the PFN characteristic, not part of the RHIC beam abort requirement. Hence, it has no significance in concern of the RHIC operation.

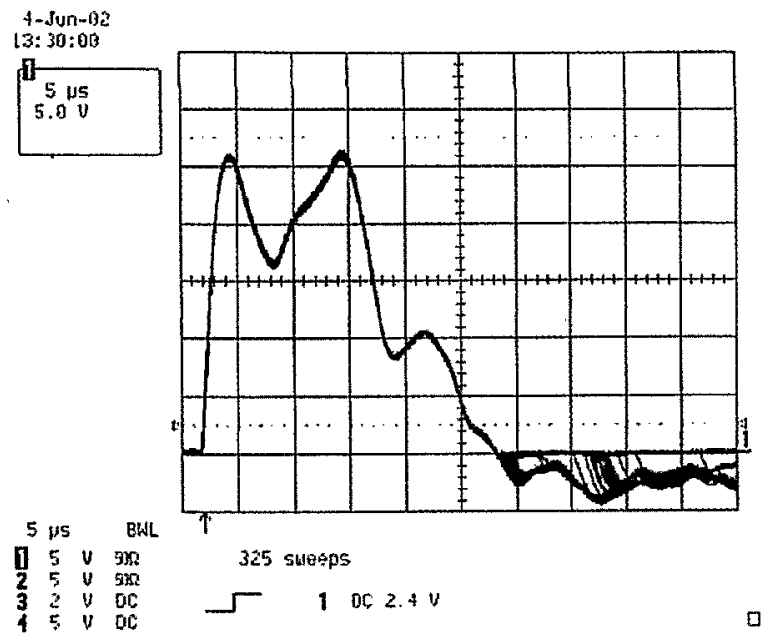

Figure 4. The out put waveform with reverse current variation at $15 \mathrm{kV}$.

To further test the gas discharge switch reverse conducting capability, a simple L-C circuit was used to create an oscillation waveform. At $30 \mathrm{kV}$ level, the output current is about $+/-14 \mathrm{kA}$. As shown in Figure 5, the switch was conducting well in both directions.

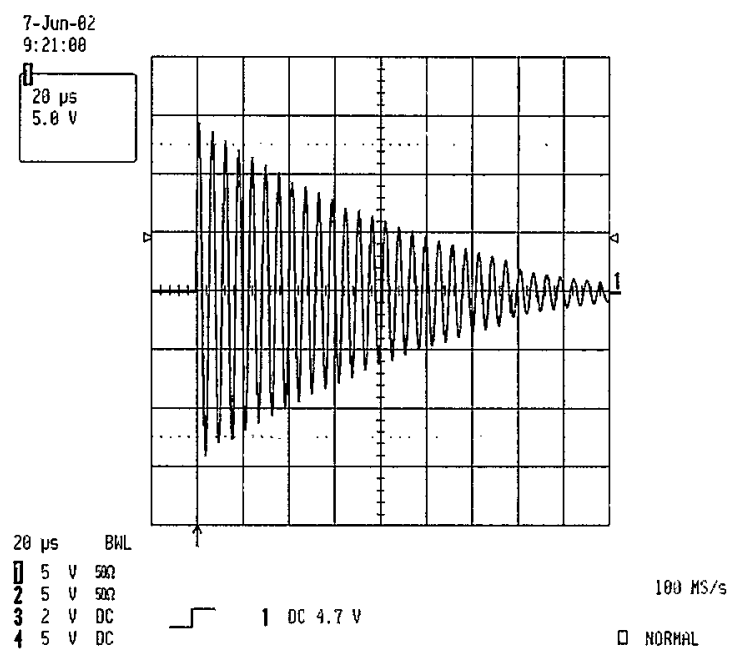

Figure 5. Oscillating current at $30 \mathrm{kV},+/-14 \mathrm{kA}$.

In Figure 6, the same output current was displayed with a time scale of $5 \mu \mathrm{S}$ per time division. We did not operate the gas discharge switch very long in this mode, and might try it later for other applications. The $14 \mathrm{kA}$ reverse current conducted during this test is very close to the manufacture's device test limit.

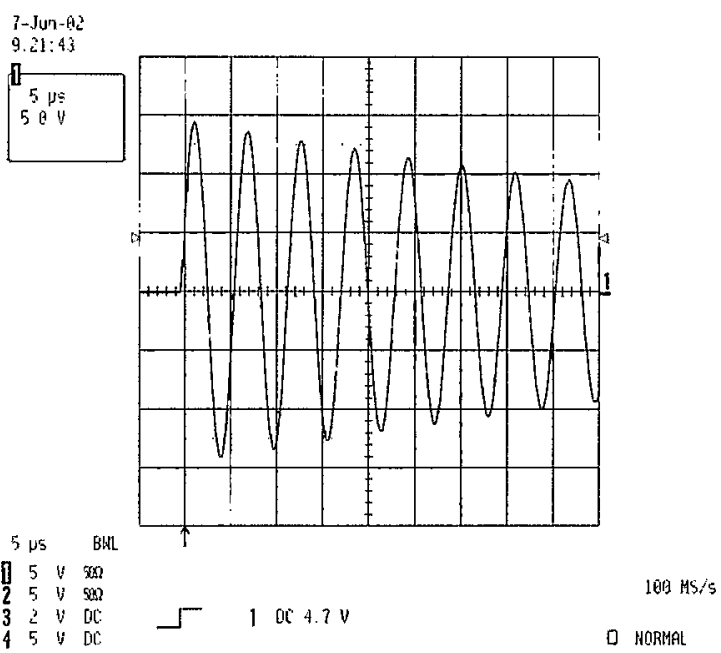

Figure 6. Oscillating Current waveform at $30 \mathrm{kV},+/-14$ $\mathrm{kA}$ operating condition.

The HX3002 was hi-potted at $35 \mathrm{kV}$ for several hours, after being pulse tested at $21.69 \mathrm{kA}$ level and oscillating tested at $+/-14 \mathrm{kA}$. No sign of voltage hold-off degradation has been observed.

\section{SWITCH COMPARISON}

The occasional RHIC Beam Abort Kicker thyratron premature firing has been a serious problem during the RHIC operation. When one of the five high voltage modulators self-conducts, the circulating beam will be partially deflected from its designed orbit and spread onto down stream ring components and detectors. Even a tiny amount of high energy beam deposit on vulnerable silicon detectors or superconducting magnets may cause destructive damage. The operation voltage of the Blue Ring Beam Abort Kicker was lowered to $22 \mathrm{kV}$ during last run to reduce the chance of thyratron misfiring. It shall be pointed out that the thyratron voltage hold-off degradation is only part of the problem. Corona marks have been found on a high voltage connecting plate between thyratron anode and the first PFN capacitor. Therefore, the deficiency of the modulator high voltage design and construction contributed largely to the overall misfiring problem. All high voltage modulators will be modified to improve performance.

\section{A. Reverse Current Conduction}

The CX1575C and CX3575C thyratron degradation have been reported in [4] and [5]. These thyratrons have the hollow anode structure and serve primarily for laser application, where reverse current is usually small and much shorter in duration. The RHIC beam Abort Kicker has a $30 \mu \mathrm{S}$ long reverse current swing, which requires a large amount of plasma beyond the capability of the 
hollow anode cavity. The HX3002 Gas Discharge Switch is capable of large reverse current conduction for tens of $\mu \mathrm{S}$. It is ideal for the low repetition rate, high energy pulser application.

\section{B. Operation Range}

The RHIC Beam Abort Kicker PFN voltage must track the beam energy during beam injection, acceleration, and storage. It requires an operation range from $4 \mathrm{kV}$ to 28 $\mathrm{kV}$. At lower voltage end, CX1575C and CX3575C thyratrons might be difficult to trigger and have to use higher reservoir heater voltage; this makes thyratrons more vulnerable at higher voltage hold-off during beam storage. The minimum conduction voltage of HX3002 Gas Discharge Switch is about $1 \mathrm{kV}$, which provides a very comfortable operation margin. Both devices are rated much higher than the $28 \mathrm{kV}$ required maximum operation voltage, but the peak current ratings are rather close to the limit.

\section{Device Lifetime}

The thyratron used for RHIC beam Abort Kicker application have to be operated exceeding their capability and their lifetime were severely shortened than normal application within their specification. At least seven of the ten thyratrons have to be replaced during last run. Although, the kicker was used once every eight to ten hours during normal beam storage, and somewhat more during injection and tuning at minimum energy level. For this low repetition rate application, the Gas Discharge Switch might last longer then thyratron, but more system test is needed to confirm it.

\section{Timing Jitter}

The thyratron usually has a very small timing jitter in the range of a1 to $3 \mathrm{nS}$. The $\mathrm{HX} 3002$ has a $10 \mathrm{nS}$ timing jitter. This is tolerable in the RHIC beam Abort Kicker application, which has a waveform of $1 \mu \mathrm{S}$ rise time and more than $15 \mu \mathrm{S}$ forward conduction duration.

\section{E. Device Compatibility}

The HX3002 has a small hot cathode and triggers rather like a thyratron, with a standard trigger pulse, but relies on a cold cathode electrode for high current conduction [1]. It has the same base mounting dimension of the CX1575C and CX3575C, which makes it easy to adopt mechanically.

\section{F. Other Issues}

The hollow anode thyratrons are fairly expensive. With large amount replacement of thyratrons in each run and demand for frequent service, it has become a big burden for operation budget and manpower cost. For direct price comparison, the HX3002 costs about one third of the CX3575C. In addition to it, the HX3002 is expected to require much less service and maintenance. If it will last longer then that of thyratron in the RHIC Beam Abort Kicker application, the total cost savings can be significant.

\section{CONCLUSION}

The HX3002 Gas Discharge Switch test has shown promising result. We plan to conduct more tests to verify device lifetime and stability. The dual trigger method will be evaluated for the possible improvement of the overall system high voltage hold-off capability.

We would like to thank D. Warburton, K. Hartmann, J. Addessi, S. Perlstein, and R. Zapasek for their technical support.

\section{REFERENCE}

[1] C. A. Pirrie, and C. A. Roberts, "A new Discharge Switch for Discharging high Energy Capacitor Banks", Digest of Technical papers of the Eleventh IEEE International Pulsed Power Conference, 1997, pp. 334-339.

[2] L. Ahrens, J. Mi, W. Zhang, "THE RHIC BEAM ABORT SYSTEM - OPERATION DURING THE RHIC 2001 GOLD RUN", Presented at EPAC 2002, June 2002.

[3] W. Zhang, L.A. Ahrens, J.L. Mi, B. Oerter, J. Sandberg, R. Sanders, "RHIC Beam Abort Kicker Power Supply System Commissioning Experience and Remaining Issues", IEEE Proceedings of The 2001 Particle Accelerator Conference, 2001, pp. 3711-3713.

[4] H. Hahn, A. Dunbar, C. I. Pai, R. T. Sanders, N. Tsoupas, J. E. Tuozzolo, " THE RHIC BEAM ABORT KICKER SYSTEM", IEEE Proceedings of The 1999 Particle Accelerator Conference, 1999, pp. 1100-1102.

[5] H. Hahn, "Test Results CX3575C \#1460", BNL C-A internal communication, Nov. 1999. 